\title{
Distribution, métabolisme et rôle du sorbitol chez les plantes supérieures. Synthèse
}

\author{
AJ Escobar Gutiérrez *, JP Gaudillère ** \\ Station de physiologie végétale, Centre de recherches de Bordeaux, Inra, F-33883 Villenave-d'Ornon cedex, France
}

(Reçu le 24 octobre 1995 ; accepté le 25 mars 1996)

\begin{abstract}
Résumé - Le sorbitol est l'un des 17 alditols trouvés chez les plantes supérieures. II est, avec le saccharose, un produit majeur de la photosynthèse chez plusieurs espèces de la famille des Rosaceae et des Plantaginaceae. L'accumulation de sorbitol permet une réponse adaptative des plantes soumises à des stress salins, hydriques et aux basses températures. La biosynthèse de sorbitol est confinée aux organes source et sa dégradation n'a lieu que dans les organes puits. La synthèse de sorbitol est en compétition avec celle du saccharose car ils ont un précurseur commun, le glucose-6-phosphate. Les mécanismes qui contrôlent et régulent la partition de carbone entre ces deux voies restent mal connus. Néanmoins des effets de l'environnement et les conditions de culture peuvent jouer un rôle important en modifiant les flux métaboliques entre le sorbitol, le saccharose et l'amidon.
\end{abstract}

alditol / Plantaginaceae / photosynthèse / phylogénétique / Rosaceae

Summary - Distribution, metabolism and role of sorbitol in higher plants. A review. Sorbitol is one of the 17 sugar alcohols or alditols found in higher plants. It is a major final product of photosynthesis and, together with sucrose, represents the main form of carbon translocated in many species of the Rosaceae and Plantaginaceae families. Sorbitol accumulation is considered as an adaptative response of plants to drought, salinity or chilling stress. Biosynthesis of sorbitol is confined mainly to source leaves whereas metabolic utilization is restricted to sink tissues. Sorbitol synthesis is in competition with sucrose synthesis because they have a common pathway from triosephosphate to glucose-6-phosphate. The control mechanisms of cellular carbon partitioning into sorbitol versus sucrose and starch in source leaves remains unknown. However partitioning appears to be affected by environmental factors.

alditol / Plantaginaceae / photosynthesis / phylogenetic / Rosaceae

\section{INTRODUCTION}

Chez la plupart des espèces cultivées, le saccharose et l'amidon sont les principaux produits de la photosynthèse. Le saccharose est la principale forme de transport de carbone et une forme de stockage glucidique. L'amidon est une forme de stockage du carbone dans les feuilles et certains organes spécialisés. Cependant, au sein de nombreuses espèces de végétaux inférieurs et

\footnotetext{
* Adresse permanente : Instituto de Recursos Naturales, Colegio de Postgraduados en Ciencias Agricolas, 56230 ChapingoMontecillo, Mexique

${ }^{\star \star}$ Correspondance et tirés à part
} 
supérieurs, les sucres alcools ou alditols sont à la fois des produits majeurs de la photosynthèse et des composés assurant aussi le transport et le stockage de carbone photoassimilé. Les fonctions physiologiques attribuées aux alditols sont nombreuses et analogues à celles du saccharose. Outre le stockage et le transport de carbone le sorbitol représente une source de pouvoir réducteur et contribue à la régulation osmotique, la cryoprotection et la protection d'enzymes.

Dans cette revue, nous présentons l'état actuel des connaissances concernant la distribution phylogénétique et le métabolisme du sorbitol chez les plantes supérieures. Dans certains cas, nous avons fait référence à des informations sur le mannitol du fait de ses analogies fonctionnelles et métaboliques avec le sorbitol. L'intérêt porté aux rôles du sorbitol a été renouvelé par la possibilité de l'introduire par des transformations génétiques chez des espèces qui naturellement ne sont pas capables de l'accumuler.

\section{Les alditols ou sucres alcools}

\section{Les polyols}

Un alcool résulte du remplacement d'un atome d'hydrogène dans un hydrocarbure aliphatique par un groupement hydroxyle $(-\mathrm{OH})$. Les polyols sont des alcools présentant plus de deux groupements hydroxyle. Ils sont nommés aussi polyalcools ou alcools polyhydriques.

\section{Classification des polyols naturels}

Les polyols peuvent être classés en 2 groupes comprenant les alditols qui ont une chaîne linéaire d'atomes de carbone, appelés aussi polyols aliphatiques, et les cyclitols, polyols cycliques, qui sont dérivés du cyclohexane (Plouvier, 1963).

\section{Les alditols}

Les alditols ou sucres alcools sont les composés obtenus lorsque le groupement aldéhyde ou cétone d'un sucre est réduit au groupement hydroxyle correspondant. Suivant la longueur de la chaîne carbonée, on désigne les alditols sous le nom de pentilols, hexitols, heptitols, etc. Les alditols les plus courants chez les plantes sont les hexitols (Plouvier, 1963). Chaque aldose produit un seul alditol et cette relation détermine la nomenclature de chaque alditol. Dans ces condi- tions, le D-glucose est le précurseur du D-glucitol (nommé couramment sorbitol), le D-mannose celui du D-mannitol, etc. Les noms triviaux des alditols font parfois référence à la plante à partir de laquelle ils ont été isolés pour la première fois. D'autre part, la réduction du carbone 2 des cétoses conduit à deux configurations possibles donc à deux alditols différents. La réduction du Dfructose peut donner soit du D-glucitol (sorbitol), soit du D-mannitol (Lewis, 1984a).

\section{Distribution des alditols chez les végétaux supérieurs}

La distribution des alditols chez les plantes supérieures a été décrite par Plouvier (1963), Lewis et Smith (1967), Bieleski, (1982) et Lewis (1984a,b). Les travaux de Wallaart $(1980,1981)$ permettent de compléter cette description.

\section{Les alditols chez les plantes supérieures}

Dans sa revue, Plouvier (1963) a présenté la distribution de 35 alcools aliphatiques et cyclitols chez les plantes et a discuté leur signification et leur importance dans la chimiotaxonomie. Plusieurs de ces polyols sont caractéristiques de certains taxa. Leur présence a été utilisée comme critère de classification. Cependant certains polyols se trouvent uniquement chez quelques familles particulières ou chez des espèces isolées appartenant à des familles très diverses. Dans ce cas, leur présence ne peut être considérée comme un critère de classification (Plouvier, 1963, 1971).

La présence des polyols ne permet pas de différencier les unités systématiques au dessus de la famille. Par exemple, certains botanistes incluent la famille des Fabaceae (Leguminosae) dans l'ordre des rosales, alors que d'autres ne le font pas (Rowley, 1985). Le pinitol, qui est présent chez la famille des Fabaceae, est absent chez d'autres familles des rosales. De même, le sorbitol qui est présent chez la famille des Rosaceae ne l'est pas chez les ordres des magnoliales, dilleniales ou hamamelidales qui sont phylogénétiquement liés à l'ordre des rosales (Plouvier, 1963).

II existe au moins 17 alditols naturellement présents chez les plantes (Lewis, 1984a, 1984b), dont 13 chez les angiospermes (Lewis et Smith, 1967 ; Loescher, 1987), mais quelques-uns seulement, tels que le mannitol, le sorbitol, le galactitol (D-dulcitol), l'allitol et l'hamamelitol, ont été 
étudiés du point de vue biochimique et physiologique (Lewis, 1984b).

Les alditols sont rarement rencontrés chez les angiospermes monocotylédones, et seul le mannitol (Lewis et Smith, 1967) et le sorbitol ont été détectés à faible concentration chez quelques espèces de ce groupe (Bieleski, 1982 ; Shaw et Dickinson, 1984 ; Doehlert et al, 1993). Par ailleurs, il existe plusieurs alditol connus seulement chez quelque rares espèces, fréquemment dans un seul genre ou encore, dans certains sections du même genre (Lewis et Smith, 1967).

Trois alditols sont largement distribués chez les angiospermes (fig 1). Ce sont le galactitol, le mannitol et le sorbitol. Le galactitol est présent principalement au sein des familles des Celastraceae, des Scrophulariaceae et des Orobanchaceae. Chez ces deux dernières, le galactitol coexiste avec le mannitol (Plouvier, 1963). Le mannitol est le polyol le plus répandu chez les dicotylédones. II a été recensé dans plus de 70 familles (Loescher, 1987). Le mannitol est le sucre alcool caractéristique des familles des Oleaceae et des Umbelliferae (Bieleski, 1982 ; Lewis 1984b). Le sorbitol se trouve principalement chez les familles des Rosaceae (Wallaart, 1980) et des Plantaginaceae (Wallaart, 1981).

\section{Le sorbitol chez les plantes supérieures}

À la différence du mannitol, le sorbitol n'a pas été mis en évidence chez les plantes inférieures (Bieleski, 1982).

\section{Le sorbitol chez la famille des Rosaceae}

Le sorbitol a été isolé pour la première fois par Boussingault (1872) à partir de baies mûres de sorbier (Pyrus aucuparia (L) Ehrh). Plus tard, le sorbitol a été détecté dans les fruits et les feuilles de plusieurs espèces de cette famille (Plouvier, 1963). Les premières études concernant la présence de sorbitol chez les plantes et plus particulièrement dans les fruits, ont été motivées par un intérêt purement économique. En effet, le but poursuivi consistait à détecter l'adultération des jus de fruit et d'autres produits de fruits sans sorbitol à l'aide de produits moins onéreux obtenus à partir de pommes ou de poires et donc contenant du sorbitol. Plus tard, l'intérêt diététique du sorbitol a également stimulé la recherche (Wallaart, 1980). Plouvier (1963) a été le premier à remarquer l'importance du sorbitol pour la classification intra-famille des Rosaceae. En effet, la famille des Rosaceae est la seule de l'ordre des rosales où le sorbitol est présent. Le sorbitol est commun aux sous-familles des Spiraeoideae,

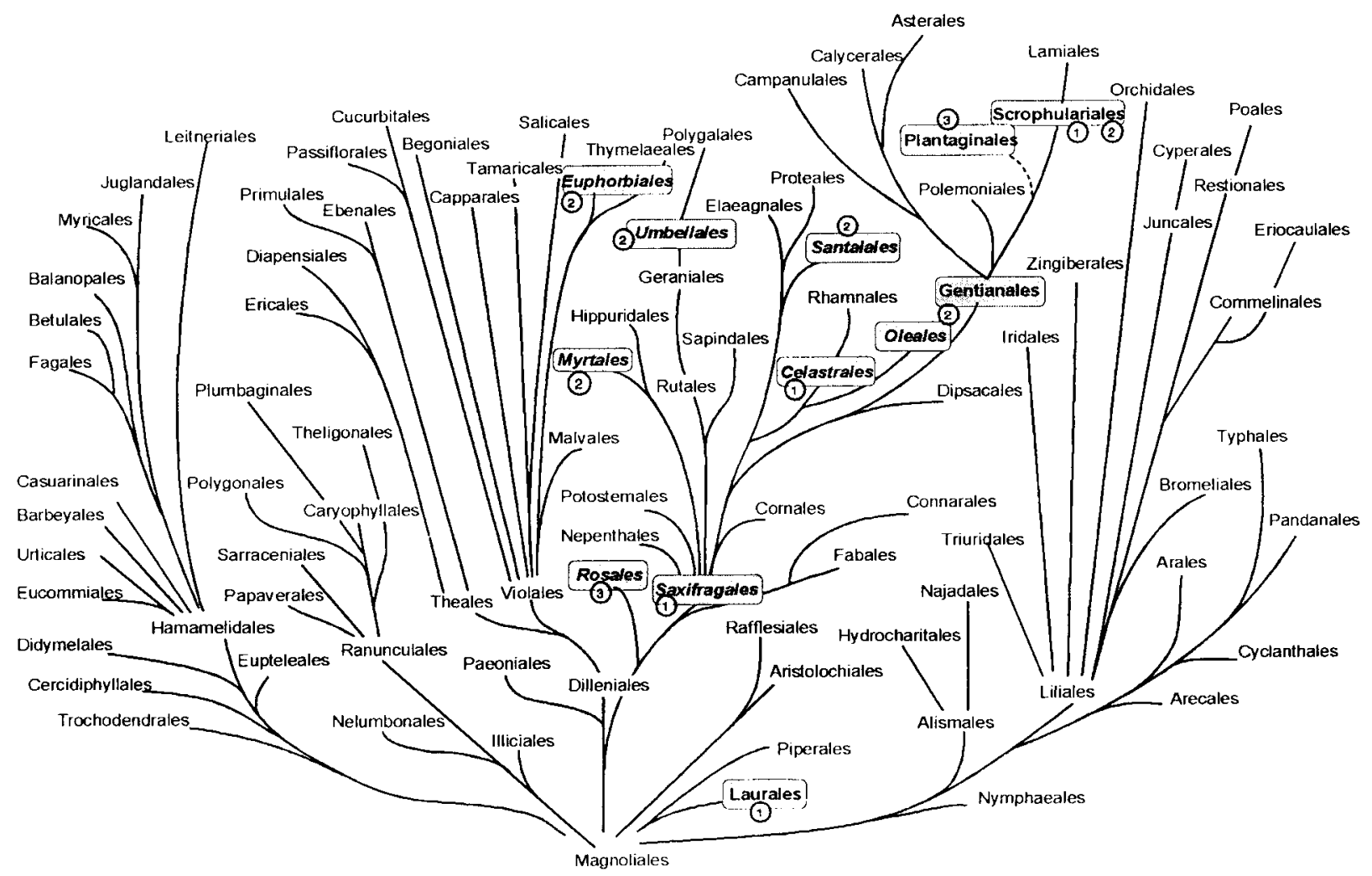

Fig 1. Arbre phylogénétique de Takhtajan (Raynal-Roques, 1994). Les ordres umbellales et plantaginales ont été ajoutés d'après Heywood (1985). Les ordres contenant des espèces à hexitol sont marqués avec : 1 , galactitol; 2 , mannitol et 3 , sorbitol (d'après Plouvier, 1963; Wallaart, 1981; Lewis, 1984a). 
des Maloideae et des Prunoideae (Plouvier, 1963 ; Wallaart, 1980). Wallaart (1980) a proposé que la tribu Kerrieae, avec ses genres Rhodotypos, Kerria, Neviusia et Coleogyne, de même que la tribu Adenostomeae, soient transférées de la sous-famille des Rosoideae à la sousfamille des Spiraeoideae du fait que ce sont les seuls genres chez lesquels le sorbitol peut être trouvé au sein des Rosoideae. Certains autres taxonomistes avaient déjà placé les genres Rhodotypos, Kerria et Neviusia a côté de Spiraea chez la sous-famille des Spiraoideae (Plouvier, 1963 ; Wallaart, 1980) ou avaient considéré les Kerrieae comme une sous-famille à part (Wallaart, 1980). Il existe une corrélation très nette entre la présence de sorbitol et le nombre de chromosomes de base chez les Rosaceae : si $n=7$, il n'y a pas de sorbitol dans les feuilles (Wallart, 1980). Les analyses de sève xylémienne des Rosaceae confirment les résultats antérieurs. Le sorbitol est présent dans la sève des plantes des sous-familles des Spiraeoideae, des Maloideae et des Prunoideae mais il est absent chez les plantes de la sous-famille des Rosoideae (Ziegler, 1975).

\section{Le sorbitol chez la famille des Plantaginaceae}

La présence de sorbitol chez les Plantaginaceae n'a jamais été analysée au point de vue de l'évolution phylogénétique des espèces végétales. Elle a été rapportée pour la première fois en 1957 (Maas, 1957, cité par Wallaart, 1981). La famille des Plantaginaceae est la seule famille dans l'ordre des plantaginales (super-ordre Asteridae). Elle est composée d'environ 253 espèces réparties dans trois genres (Plantago 250 espèces, Littorella 2 espèces et Bougueria 1 seul espèce). Cette famille n'a pas de valeur économique et quelques espèces du genre Plantago sont des adventices des cultures ou mauvaises herbes (Moore, 1985).

Wallaart (1981) a analysé les feuilles de 10 espèces de Plantago et de Littorella uniflora (L) Aschers. Toutes contiennent du sorbitol et certaines espèces comme $P$ coronopus $L$ et $P$ carinata Schrad contiennent aussi du mannitol. L'auteur en conclut que l'accumulation de sorbitol est une caractéristique générale de cette famille.

\section{Le sorbitol chez d'autres espèces}

En dehors des familles des Rosaceae et les Plantaginaceae, le sorbitol est retrouvé chez quelques autres espèces. Malheureusement, l'information étant limitée et dispersée, on ignore si la présence de sorbitol est occasionnelle ou s'il s'agit d'une caractéristique de l'espèce, du genre ou de la famille. Quelques exemples d'espèces où le sorbitol a été détecté sont : Phoenix dactylifera et Cocos nucifera (Palmae), Quercus et Fagus (Fagaceae), Vitis vinifera (Vitaceae) (voir Bieleski, 1982) et dans les grains de maïs (Zea mays L) (Shaws et Dickinson, 1984 ; Doehlert et al, 1993). Chez ces espèces, on ignore si, comme chez les Rosaceae, le sorbitol est un produit primaire de la photosynthèse.

\section{Distribution du sorbitol dans la plante}

La distribution du sorbitol au sein de la plante, comme c'est le cas pour les autres alditols, varie avec l'espèce. Bien qu'ils se trouvent dans presque tous les organes, les teneurs les plus élevées sont observées dans les feuilles et les tiges vertes (Plouvier, 1963). En général, les organes puits, qui utilisent massivement des glucides comme source d'énergie (plantules en germination, tiges bouturées, cals) renferment moins de $15 \%$ de leurs glucides sous forme de sorbitol (Whetter et Taper, 1966 ; Chong, 1971 ; Bieleski, 1982).

Il est intéressant de noter que le sorbitol, de même que les autres alditols, peut être absent de certains organes ou du nectar floral des plantes qui synthétisent massivement cet alditol (Bieleski et Redgwell, 1980 ; Bieleski, 1982 ; Lewis, 1984b).

\section{Feuilles}

Il est bien établi que chez les plantes supérieures autotrophes, le sorbitol est produit à partir des trioses-phosphate issus de la photosynthèse (voir «Métabolisme») (Escobar-Gutiérrez, 1995). En conséquence, les taux de sorbitol dans les feuilles sont étroitement liés à l'activité métabolique de la feuille en particulier, et de la plante en général. En effet, les feuilles adultes sont le principal site de synthèse du sorbitol, et des différences de teneur entre jeunes feuilles et feuilles adultes ont été rapportées chez l'abricotier (Bieleski et Redwell, 1985), le pommier (Loescher et al, 1982) et le pêcher (Merlo et Passera, 1991). L'exception à cette règle pourrait être Prinsepia sinensis Oliv où les très jeunes feuilles ont des teneurs en sorbitol très élevées (Wallaart, 1980).

Des différences de concentration en sorbitol entre le limbe $(3,4 \%$ de la matière sèche) et le 
pétiole $(5,8 \%$ de la matière sèche) ont été observées chez Plantago major L (Wallaart, 1981).

Le taux de sorbitol dans les feuilles présente une grande variabilité au sein des sous-familles des Spiraeoideae, des Maloideae et des Prunoideae, chez lesquelles il représente respectivement $1,3-11,6 \%, 2-8,7 \%$ et $3-17 \%$ de la matière sèche (Wallaart, 1980). Chez les feuilles adultes de pêcher, les teneurs en sorbitol sont fréquemment le double de celles en saccharose (Escobar-Gutiérrez et Gaudillère, 1994).

Les teneurs en sorbitol des feuilles peuvent être fortement modifiées par les conditions environnementales (Chong et Taper, 1971a) et de culture (Ranney et al, 1991 ; Gaudillère et Moing, 1992 ; Wang et Stutte, 1992 ; Escobar-Gutiérrez, 1995). Ainsi, Chong et Taper ont montré que la teneur en sorbitol des feuilles est corrélée avec la température de l'air (1971a) et le rayonnement solaire cumulé (1971b).

\section{Fleurs}

Le tissu des nectaires floraux est riche en sorbitol alors que le nectar n'en contient que peu. Bieleski et Redgwell (1980) ont démontré que le nectar des fleurs d'abricotier, de pêcher, de poirier, de pommier, de prunier japonais et de quatre autres Rosaceae ligneuses contiennent très peu de sorbitol par rapport aux sucres totaux (moyenne $=1,6 \%$ des sucores).

\section{Fruits}

Le sorbitol est la principale forme de transport de carbone dans le phloème chez les Rosaceae (Zimmerman et Ziegler, 1975 ; Bieleski et Redgwell, 1985 ; Moing et al, 1992). Toutefois, les fruits contiennent en général très peu de sorbitol. Sa teneur varie beaucoup en fonction de l'espèce, de la variété ou encore de l'état physiologique du fruit (Bieleski, 1982). De plus, il est possible que la teneur soit irrégulièrement répartie à l'intérieur du fruit (Chong et al, 1972, cité par Bieleski, 1982).

Les fruits du sorbier, de Photinia arbutifolia, de Cotoneaster $\mathrm{sp}$, ainsi que la prune, la poire et la poire du Japon (Pyrus mume Sieb et Zucc) contiennent plus de $2 \%$ de la matière fraîche sous forme de sorbitol, ce qui représente plus de $50 \%$ des glucides solubles. En revanche, la nèfle, l'abricot, la cerise (Bieleski, 1982) et la pomme (Bieleski, 1982 ; Marlow et Loescher, 1985) contiennent environ $0,5 \%$ de la masse fraîche sous forme de sorbitol, ce qui représente $5 \%$ des glucides solubles.

Plusieurs études ont montré que chez les pêches mûres, le glucide majeur est le saccharose, suivi par des sucres réducteurs (glucose et fructose) et de faibles quantités de sorbitol, qui représente moins de $10 \%$ des glucides solubles (Moriguchi et al, 1990 ; Brooks et al, 1993 ; Pavel et DeJong, 1993).

Même au sein d'une espèce, la concentration du sorbitol peut varier selon le cultivar. Chez la pêche, Brooks et al (1993) ont étudié les teneurs en glucides de 54 lignées sélectionnées issues de semis et de quatre populations issues de semis. La concentration moyenne en sorbitol pour les sélections est de $0,42 \%$ de la masse fraîche alors que la moyenne des quatre populations évaluées est un peu plus élevée $(0,8 \%)$. Chez certaines de ces populations, le sorbitol atteint 10 $\%$ des sucres solubles (Brooks et al, 1993).

Selon Brooks et al (1993), les pêches dites de «bonne qualité" contiennent un taux de fructose plus élevé et moins de glucose et de sorbitol que les pêches dites de "mauvaise qualité». Dans le deuxième cas, les taux de sorbitol et des autres sucres, montrent une ségrégation transgressive. II est donc possible de sélectionner des plantes qui produisent des fruits contenant moins de sorbitol et plus de saccharose et d'hexoses que leurs parents. L'héritabilité calculée pour le taux de sorbitol est plus élevée que pour les autres sucres du fruit (Brooks et al, 1993).

Certains génotypes de maïs peuvent contenir du sorbitol dans leurs grains, bien qu'il ne soit pas détectable dans les autres organes, y compris les feuilles (Shaw et Dickinson, 1984 ; Doehlert et al, 1993). Ce sorbitol peut représenter jusqu'à $4,4 \%$ des sucres solubles totaux (Doehlert et al, 1993).

Le sorbitol est absent des akènes des Plantaginaceae (Lewis, 1984b) où l'on trouve un oligosaccharide, le plantéose, qui, à l'inverse, est absent des parties végétatives.

\section{Graines}

Chez certaines espèces riches en alditols, ces composés peuvent être absents des graines. C'est le cas du mannitol absent des graines des Oleaceae (Lewis, 1984b). Dans les graines de pommier, où le principal sucre soluble est le fructose, le sorbitol représente moins de $15 \%$ de la masse des sucres solubles (Whetter et Taper, 1966). 


\section{Sève}

La concentration en sorbitol est particulièrement élevée dans la sève phloémienne. En effet, le sorbitol représente entre 60 et $90 \%$ du carbone exporté à partir des feuilles de pommier (Bieleski, 1969 ; Hansen, 1970 ; Bieleski, 1982). Les exudats des tubes criblés de pommier (Webb et Burley, 1962) ainsi que la sève phloémienne de pêcher obtenue par stylectomie (Moing et al, 1992 ; Escobar-Gutiérrez, 1995) contiennent du sorbitol et du saccharose comme glucides majeurs.

Le sorbitol est présent dans la sève xylémienne ainsi que dans le bois et l'écorce de pommier (Williams et Billingsley, 1973 ; Williams et Raese, 1974 ; Hansen et Grausland, 1978 ; Raese et al, 1978 ) et dans sa sève xylémienne de pêcher (Zipperlin, 1993).

\section{Compartimentation cellulaire du sorbitol}

Peu d'études ont été réalisées sur la compartimentation subcellulaire du sorbitol, et des alditols en général. Les résultats de Yamaki (1982) ont montré que $54 \%$ du sorbitol des coylédons de pommier se trouvent dans la vacuole. La totalité du sorbitol (2\% de la masse des sucres solubles) de l'endocarpe des pommes est vacuolaire (Yamaki, 1984), mais les techniques utilisées dans ce cas ne permettent pas de tirer des conclusions définitives. Dans les cellules parenchymateuses des rachis foliaires de céleri (Apium graveolens L), $72 \%$ du mannitol est localisé dans la vacuole (Keller et Matile, 1989).

\section{Variations nycthémérale et saisonnière de la concentration en sorbitol}

Dans les parties végétatives et dans les fruits, la concentration en sorbitol varie d'une façon journalière et saisonnière, et différemment selon l'espèce. Ces observations suggèrent que quelques alditols peuvent être rapidement métabolisés mais que d'autres, malgré une synthèse rapide, ne peuvent être transformés que très lentement (Lewis et Smith, 1967).

\section{Variation nycthémérale}

Chong et Taper (1971a) ont observé une importante variation journalière de la teneur en sorbitol dans les feuilles de pommier. Ainsi, la diminution de la teneur en sorbitol observée pendant la nuit est suivie d'une très forte accumulation le jour suivant. Des résultats similaires ont été observés par Chong (1971) dans les feuilles de semis de pommier. Cet auteur présente également les profils d'évolution nycthémérale de la teneur en sorbitol dans l'écorce des tiges et des racines.

Chez les feuilles de Plantago coronopus L, le taux de sorbitol augmente durant la période d'éclairement (Lambers et al, 1981). L'évolution de ce taux pendant la nuit qui succède, dépend de la concentration en $\mathrm{NaCl}$ de la solution nutritive. Dans les racines, le sorbitol s'accumule au cours de la journée et sa teneur diminue pendant la nuit, et ce, indépendamment de la composition de la solution nutritive.

\section{Variation saisonnière}

\section{Variation saisonnière dans les parties végétatives}

Des études anciennes ont montré que dans les feuilles d'olivier (Olea europeae L) et de Gardenia sp, la teneur en mannitol augmente pendant l'hiver et diminue pendant l'été (Nuccorini, 1930 et Asai, 1937, cités par Lewis et Smith, 1967).

Les variations saisonnières de la concentration en sorbitol ont fait l'objet de nombreuses études chez les pommier (Whetter et Taper, 1963 ; Taper et Liu, 1969 ; Chong, 1971 ; Chong et Taper, 1971a, b ; Hansen et Grausland, 1973; Williams et Billingsley, 1973) et chez d'autres espèces (Sakai, 1961, 1966 ; Rohrbach et Luepschen, 1968 ; Wallaart, 1981 ; Gaudillère et al, 1992).

Chez le pommier, les résultats sont contradictoires, mais ils indiquent pour la plupart que les teneurs maximales en sorbitol s'observent pendant l'été. Toutefois, le profil d'évolution précis dépend du tissu analysé et des conditions du milieu. En effet, les résultats de Chong et Taper (1971b) ont établi qu'une forte corrélation existait entre la concentration saisonnière en sorbitol et le rayonnement solaire cumulé. De même, une corrélation significative existe entre la teneur en sorbitol des feuilles au cours de l'été et la température de l'air (Chong et Taper, 1971a). La teneur en sorbitol dans la sève xylémienne de pommier varie de manière saisonnière (Williams et Billingsley, 1973 ; Hansen et Grausland, 1978) et en fonction du cultivar (Williams et Billingsley, 
1973). En effet, Williams et Raese (1974) ont observé chez des pommiers dormants une accumulation de sorbitol dans le bois et la sève xylémienne.

Selon Wallaart (1981), les teneurs en sorbitol et en mannitol chez les Plantaginaceae peuvent varier largement au sein d'une même espèce. Cependant, aucune corrélation n'a pu être établie entre la teneur en sorbitol ou en mannitol, ainsi que la saison, les paramètres géographiques ou écologiques du site de prélèvement des plantes analysées.

Dans l'écorce de pêcher, la teneur en sorbitol la plus basse est observée pendant le mois de janvier, et la plus forte en août (Rohrbach et Luepschen, 1968). Dans le bois du tronc de prunier, les teneurs en sorbitol varient peu au cours de l'année (Gaudillère et al, 1992).

\section{Variation saisonnière dans les fruits}

La teneur en sorbitol peut changer au cours du développement du fruit et pendant son stockage après récolte. Ainsi, chez la pomme, le sorbitol diminue au cours du mûrissement sur l'arbre (Taper et Liu, 1969 ; Chan et al, 1972 ; Berüter et Kalberer, 1983 ; Berüter, 1985, 1989), puis il augmente pendant le stockage (Taper et Liu, 1969 ; Chan et al, 1972). Par ailleurs, une augmentation du taux de sorbitol a également été observée dans des pommes stockées pendant deux jours en conditions d'anoxie (Generozova et al, 1990). Cette augmentation s'est avérée associée à la diminution de la concentration en saccharose, en fructose, en polysaccharides et en malate, et à la perte de la structure mitochondriale et la destruction des membranes cellulaires. Par ailleurs, de fortes augmentations du taux de sorbitol peuvent être associées à des désordres physiologiques des fruits. En effet, une concentration élevée en sorbitol est l'une des caractéristiques des pommes présentant le problème de vitrescence (Williams et Billingsley, 1973 ; Marlow et Loescher, 1985). Marlow et Loescher (1985) proposent que les niveaux élevés de sorbitol sont le résultat et non la cause du problème de vitrescence. D'autre part, ces auteurs ont montré qu'il n'y a aucune corrélation entre la susceptibilité à la vitrescence et l'activité extractible de l'enzyme sorbitol déshydrogénase $(\mathrm{SDH})$ à NAD transformant le sorbitol en fructose.

Des résultats contradictoires concernant les variations saisonnières de la teneur en sorbitol ont été obtenus chez la pêche. En effet, Brooks et al (1993) ont montré que le rapport sorbitol/sucres totaux diminue de 9,1 à $6,5 \%$ au cours du mûrissement. Par contre, Moriguchi et al (1990) ont montré que le sorbitol reste stable approximativement à $10 \%$ du pool des glucides solubles totaux.

Dans l'endosperme des grains de maïs dit sucré, la concentration en sorbitol diminue de 1 à $0,5 \%$ de la masse sèche au cours de la maturation (Doehlert et al, 1993).

\section{Rôles physiologiques du sorbitol chez les plantes}

Lewis et Smith (1967) ont été les premiers à proposer quatre rôles physiologiques. Les alditols sont des composés de transport et de stockage glucidique mais ils peuvent aussi avoir des fonctions de cryoprotection et d'osmorégulation.

\section{Transport}

En comparant la composition en sucres de la sève phloémienne chez plus de 500 espèces, Ziegler (1975) a identifié trois types de plantes. Dans le premier groupe, il place les espèces ayant le saccharose comme sucre prédominant. Le deuxième groupe est caractérisé par la présence de quantités importantes d'oligosaccharides en plus du saccharose. Dans le troisième groupe, les sucres alcools sont présents à fortes concentrations et coexistent toujours dans la sève avec le saccharose et parfois avec des oligosaccharides. Zimmermann et Ziegler (1975) ont établi une liste des espèces qui présentent des alditols dans les exsudats phloémiens.

Webb et Burley (1962) ont été les premiers à considérer le sorbitol comme étant, avec le saccharose, le composé majeur pour le transport des glucides dans le phloème chez le pommier et d'autres Rosaceae. Leurs résultats ont été confirmés plus tard par marquage du sorbitol à partir du ${ }^{14} \mathrm{CO}_{2}$ par Bieleski (1969) et Hansen (1970) chez le pommier et récemment par des analyses de sève phloémienne obtenue par stylectomie (Moing et al, 1992 ; Escobar-Gutiérrez, 1995).

Les mécanismes de chargement et déchargement des alditols dans le phloème ont été très peu étudiés par rapport à ceux du saccharose. Daie (1987) a rapporté un mécanisme d'absorption du mannitol par des segments isolés de phloème composés de tubes criblés, de cellules compagnes, et de parenchyme phloémien. Cet 
auteur propose un chargement apoplastique du phloème.

Les travaux récents de Nii et al (1994) suggèrent une relation entre la structure des parois nacrées des tubes criblés et la présence de sorbitol dans la sève, en comparant des espèces rosacées ligneuses avec des espèces des genres Citrus ou Vitis.

\section{Stockage}

Les teneurs élevées en sorbitol ou en autres polyols chez de nombreuses espèces révèlent le rôle de ces composés en tant que réserves glucidiques. En effet, Drew (1984) a arbitrairement défini un glucide de réserve comme étant celui dont la teneur représente plus de $1 \%$ de la masse sèche du tissu dans lequel il se trouve. Le taux des alditols dans les feuilles peut atteindre, sur la base de la matière sèche, des valeurs remarquables chez certaines espèces telles que 5-8 \% de galactitol chez Euonymus alata (Negm, 1986), $9 \%$ de sorbitol chez Plantago maritima (Briens et Larher, 1983), $10 \%$ de mannitol chez le céleri (Fellmann et Loescher, 1987), $16 \%$ de mannitol chez Striga $\mathrm{sp}$, une espèce hémiparasite (Keller, 1989), et $17 \%$ de sorbitol chez Prinsepia sinensis Oliv (Prunoideae) (Wallaart, 1980).

Les alditols s'accumulent à l'état libre. Ils sont fréquemment transportés et servent de glucides de réserve à la place des oligosaccharides. Les oligosaccharides constitués par des chaînes d'alditols sont très rares dans les plantes supérieures (Lewis et Smith, 1967).

Dans les feuilles, les profils de variation journalière du sorbitol et de l'amidon sont très similaires et renforcent l'idée du rôle que le sorbitol joue en tant que composés de réserve transitoire (Chong et Taper, 1971a). Whetter et Taper (1966) ont considéré le sorbitol comme une forme de réserve glucidique dans les semences et les cotylédons de pommier.

Les concentrations en sorbitol et en mannitol augmentent lorsque les plantes sont soumises à des contraintes telles que la salinité, le déficit hydrique ou le froid.

\section{Cryoprotection}

L'accumulation hivernale de mannitol observée dans les feuilles d'olivier et de Gardenia sp (voir «Variation saisonnière»), a fait penser que les alditols pouvaient jouer un rôle cryoprotecteur.
Cependant, Sakai (1961) a montré qu'aucune corrélation n'existait entre la résistance au froid et les teneurs en alditols chez 17 espèces ligneuses. Pourtant, la question reste posée puisque au cours de l'hiver les polyols peuvent représenter plus de $40 \%$ des sucres solubles dans l'écorce des rameaux. De plus, dans des pommiers dormants une augmentation de la teneur en sorbitol dans la sève des tracheiides et les parenchymes xylémiens des tiges est associées à des températures basses (Williams et Raese, 1974). En fin, Raese et al (1978) ont conclu que la résistance au froid des tiges de pommier excisées est corrélée avec des fortes concentrations en sorbitol dans la sève et en saccharose et sucres solubles totaux dans l'écorce et le bois. Toutefois, l'accumulation de sucres solubles a été aussi associée à la diminution de la température chez plusieurs espèces ligneuses chez lesquelles les alditols ne sont pas présents (Fromard, 1990).

Bieleski (1982) a proposé que les alditols jouent un rôle cryoprotecteur, d'une part en diminuant le point de congélation de l'eau, d'autre part en protégeant les systèmes enzymatiques dans les tissus congelés. Cependant, le point de congélation de l'eau est diminué seulement de $1,86^{\circ} \mathrm{C}$ lorsque la concentration de soluté est de $1 \mathrm{M}$. Des concentrations similaires en sorbitol seraient plutôt rares chez les tissus des Rosaceae («Distribution du sorbitol dans la plante»).

Dans les feuilles du néflier du Japon (Eriobotrya japonica Lindl), la quantité et l'activité de la sorbitol-6-phosphate déshydrogénase, enzyme clé de la synthèse du sorbitol, augmentent lorsque les plantes sont soumises à une température basse (Hirai, 1983).

\section{Contrôle osmotique}

Du fait de sa structure, on a supposé que le sorbitol pourrait avoir un rôle d'osmoticum compatible chez des plantes soumises à un stress salin (Ahmad et al, 1979 ; Jefferies et al, 1979 ; Briens et Larher, 1983). Le sorbitol est accumulé dans la tige et la racine de Plantago maritima $\mathrm{L}$ et d'autres espèces de la famille des Plantaginaceae, lorsque les plantes sont soumises à de fortes concentration en sels (Ahmad et al, 1979 ; Jefferies et al, 1979 ; Lambers et al, 1981 ; Briens et Larher, 1983), ou à des solutions nutritives à faibles potentiels osmotiques (Jefferies et al, 1979). L'accumulation de sorbitol 
est plus importante dans la racine que dans la tige (Jefferies et al, 1979).

L'implication du sorbitol dans l'ajustement osmotique des feuilles de cerisier (Ranney et al, 1981) et de pommier (Wang et Stutte, 1992) soumis à des contraintes hydriques a été récemment proposée. Chez le pommier, le sorbitol pourrait représenter plus de $50 \%$ de l'ajustement osmotique total (Wang et Stutte, 1992).

La plante hémiparasite des racines, Thesium humile Vahl, accumule notamment du mannitol lors d'une contrainte hydrique de l'hôte (Simier et al, 1993). L'accumulation de ce soluté contribuerait à une diminution du potentiel osmotique du parasite, permettant les entrées d'eau à partir de l'hôte.

Récemment, Suleman et Steiner (1994) ont montré que la résistance des feuilles de pommier aux infections par Erwinia amylovora augmente avec leur âge. Cette résistance peut s'expliquer par une diminution du potentiel osmotique (plus négative) des feuilles adultes résultant d'une augmentation de leur concentration en sorbitol.

\section{Plantes transformées}

Le rôle osmoprotecteur du mannitol a été montré directement par transformation génétique de plants de tabac (Nicotiana tabacum L). Le gène d'Escherichia coli codant pour l'enzyme mannitol1-phosphate déshydrogénase (E.C.1.1.1.17) a été introduit dans le génome de tabac (Tarczynski et al, 1992). Les plantes transformées étaient capables de synthétiser cette protéine et d'accumuler du mannitol ( $100 \mathrm{mM})$ dans leurs feuilles et racines, ce qui leur pemettait de résister à la présence de $250 \mathrm{mM}$ de $\mathrm{NaCl}$ dans la solution de culture. Les plantes non transformées ne contenaient pas de mannitol et leur croissance en milieu salin s'est avérée assez limitée (Tarczynski et al, 1993). Ce rôle protecteur des polyols ne serait pourtant pas dû à un effet osmoprotecteur général mais plutôt à un effet spécifique sur des structures cellulaires. En effet, des plantes d'Arabidopsis également transformées pour synthétiser du mannitol acquièrent une résistance à la salinité bien que la concentration en mannitol des tissus ne soit que de quelques mM (Thomas et al, 1995).

Des tabacs transformés pour exprimer la sorbitol-6-phosphate deshydrogénase et qui accumulent du sorbitol ont été récemment obtenus (Tao et al, 1995). Leur capacité à résister à des stress salins ou hydriques n'ont pas encore été évaluées. Ce travail montre cependant que la sorbitol-6-phosphate déshydrogénase est bien l'enzyme clé de la synthèse du sorbitol chez les plantes.

On peut remarquer que les tissus foliaires des rosacées ligneuses contiennent naturellement des teneurs élevées en sorbitol $(400 \mathrm{mM}$, Moing et al, 1994). Elles ne sont cependant pas plus aptes à résister au stress hydrique que les plantes à saccharose (Jones et al, 1985 ; Escobar-Gutiérrez, 1995). Les espèces xérophytiques ne sont pas des espèces à polyols.

\section{La synthèse des alditols et le métabolisme énergétique}

Une caractéristique commune des voies de biosynthèse établies pour le sorbitol, le mannitol, le galactitol et le ribitol est l'utilisation de NADPH comme source de pouvoir réducteur (Keller, 1989).

La synthèse du mannitol pu être proposée comme un mécanisme alternatif de la photorespiration, dissipateur de pouvoir réducteur (Loescher et al, 1985 ; Fox et al, 1986). La biosynthèse du mannitol, de même que celle du sorbitol, nécessite du NADPH (fig 2) qui pourrait provenir de l'oxydation cytoplasmique des trioses-phosphate produits préalablement dans le chloroplaste par réduction du 3-phosphoglycérate (3-PGA) (Rumpho et al, 1983). Cette idée est discutable. Le contrôle de la photorespiration ne se situe pas au niveau de l'utilisation du pouvoir réducteur et les études de la partition du carbone récemment assimilé réalisées chez le céleri (Everard et al, 1994) et le pêcher (EscobarGutiérrez, 1995) ne suggèrent pas de modification particulière de l'activité photorespiratoire.

II a été aussi suggéré que les alditols pourraient être des formes de transport et de stockage de carbone et de pouvoir réducteur plus avantageuses pour la plante que le saccharose (Lewis, 1984b ; Keller, 1989). En effet, les alditols sont une forme de stockage d'énergie plus riche thermodynamiquement que le saccharose. La synthèse de deux moles d'hexitols à partir de quatre moles de trioses-phosphate requiert deux moles de NADPH. Le pouvoir réducteur investi pour la synthèse des alditols est entièrement récupéré lors de leur utilisation métabolique (Lewis, 1984b ; Loescher, 1987 ; Keller, 1989).

En ce qui concerne l'utilisation des nucléotides, la synthèse d'une mole de saccharose à partir de quatre moles de trioses-phosphate requiert une 


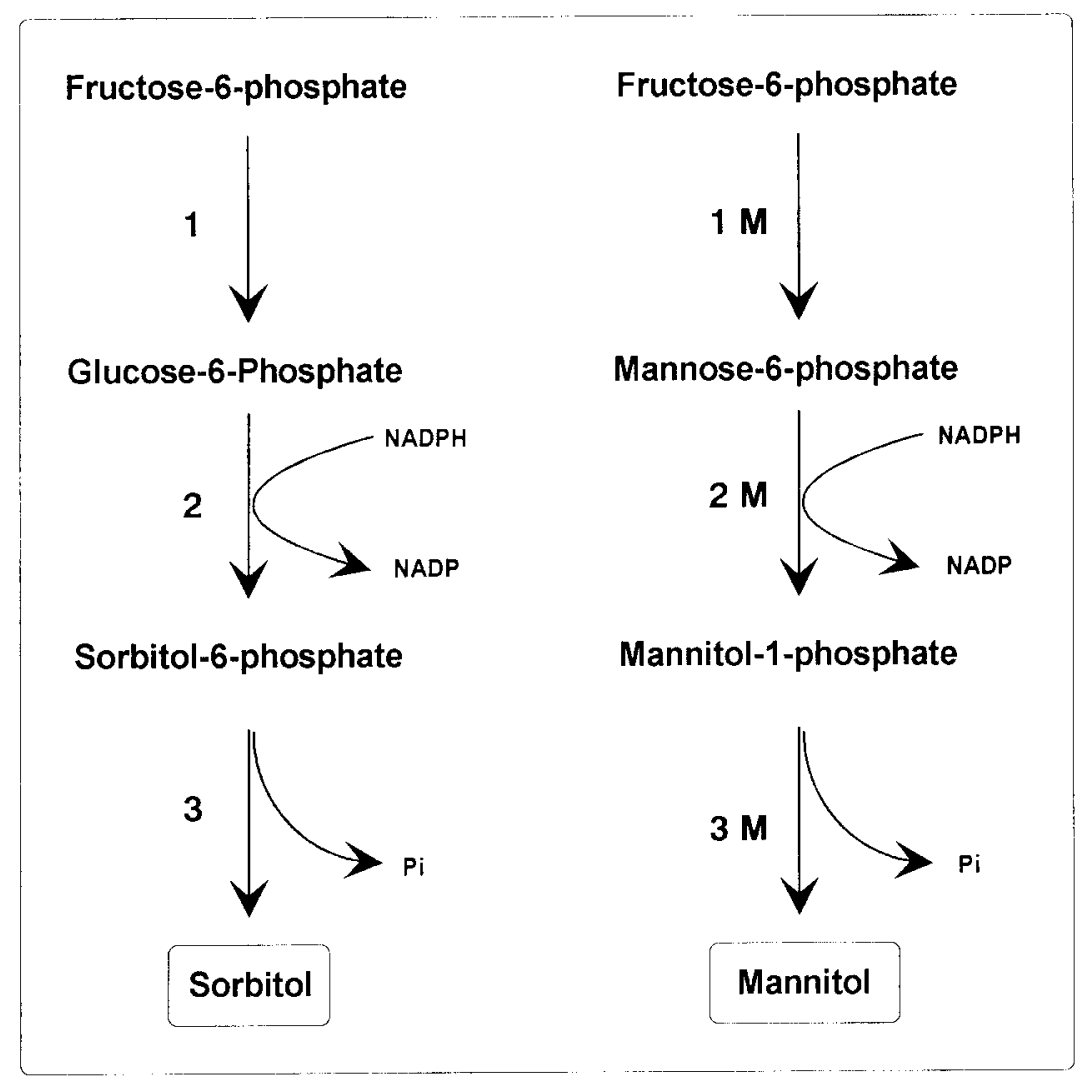

Fig 2. Voies biosynthétiques du sorbitol et du mannitol à partir de fructose-6phosphate chez les plantes supérieures (d'après Bieleski et Redgwell, 1977; Grant et ap Rees, 1981; Loescher et al, 1992). 1: phosphoglucose isomérase; 2 : alditol-6-phosphate: NADPH 1 oxidoréductase (EC 1.1.1.200); 3: sorbitol-6-phosphate phosphatase. $1 \mathrm{M}$ :mannose-6-phosphate isomérase; 2M: mannose-6-phosphate réductase; 3M: mannitol-1-phosphate phosphatase.

mole d'UTP et libère une mole d'UDP et une mole de pyrophosphate (PPi). Comparée à celle du saccharose, la synthèse de sorbitol ou de mannitol à partir du fructose-6-phosphate (fig 2) ne requiert aucune source d'énergie (UTP ou ATP) supplémentaire (Lewis, 1984b) (fig 3). Cependant, lors de l'utilisation métabolique, la transformation d'une mole de saccharose en deux moles d'hexoses-phosphate catalysée par la saccharose synthase (E.C.2.4.1.13) demande uniquement une mole d'ATP. En revanche, la transformation de deux moles d'hexitol en deux moles d'hexoses-phosphate requiert deux moles d'ATP.

\section{Métabolisme}

Le métabolisme des polyols est étroitement lié au métabolisme général des glucides.

Trois approches générales ont été utilisées pour étudier les voies métaboliques des polyols (Bieleski, 1982) : i) fourniture de ${ }^{14} \mathrm{CO}_{2}$ aux organes photosynthétiques, puis étude des produits obtenus, ii) utilisation de substrats (sucres ou polyols) marqués au ${ }^{14} \mathrm{C}$, suivie de l'analyse des métabolites, et iii) isolement et caractérisation des enzymes. De nombreuses études ont été réalisées sur des champignons (Bieleski, 1982). Dans le cas des plantes supérieures, les connaissances acquises ont été complétées ces 15 dernières années.

\section{Production photosynthétique du sorbitol}

Lorsque du ${ }^{14} \mathrm{CO}_{2}$ est fourni pendant un temps court aux organes photosynthétiques des plantes, les polyols peuvent devenir marqués très tardivement ( $>1$ heure), comme par exemple le perseitol chez l'avocat (Persea americana) (Bieleski, 1982), et le galactitol chez Evonymus japonica (Bliss et al, 1972). Cela signifie qu'ils ne sont pas des produits photosynthétiques primaires chez ces espèces qui constituent des exceptions. Le plus souvent, les polyols, de même que le saccharose, sont très rapidement marqués, ce qui indique qu'ils sont issus directement de l'activité photosynthétique. C'est le cas du sorbitol (Anderson et al, 1961 ; Bieleski et Redgwell, 1985 ; Gaudillère et al, 1991 ; Escobar-Gutiérrez, 1995), du mannitol (Rumpho et al, 1983 ; Davis et al, 1988 ; Davis et Loescher, 1990 ; Loescher et al, 1992), de l'allitol et du volemitol (Bieleski, 1982).

Hutchinson et al (1959, cités par Anderson et al, 1961) ont observé une forte incorporation de ${ }^{14} \mathrm{CO}_{2}$ dans la sorbitol des feuilles de pommier et ont suggéré un rôle central pour le sorbitol dans la métabolisme de ces feuilles. Les travaux de 
Anderson et al (1961), initialement réalisés dans le but d'étudier la biosynthèse de polysaccharides dans les feuilles de prunier (Prunus domestica L), ont confirmé ces observations. Après l'assimilation du ${ }^{14} \mathrm{CO}_{2}$, ces auteurs ont montré, par chromatographie sur papier, que le sorbitol était le seul polyol acyclique marqué dans les feuilles de prunier.
Le sorbitol apparaît comme étant un produit majeur de la fixation photosynthétique du $\mathrm{CO}_{2}$ chez le pêcher (Prunus persica (L) Batsch). En effet, dans les feuilles adultes, la synthèse du sorbitol représente plus de la moitié du $\mathrm{CO}_{2}$ récemment fixé (Gaudillère et al, 1991 ; Moing et al, 1992 ; Escobar-Gutiérrez, 1995).

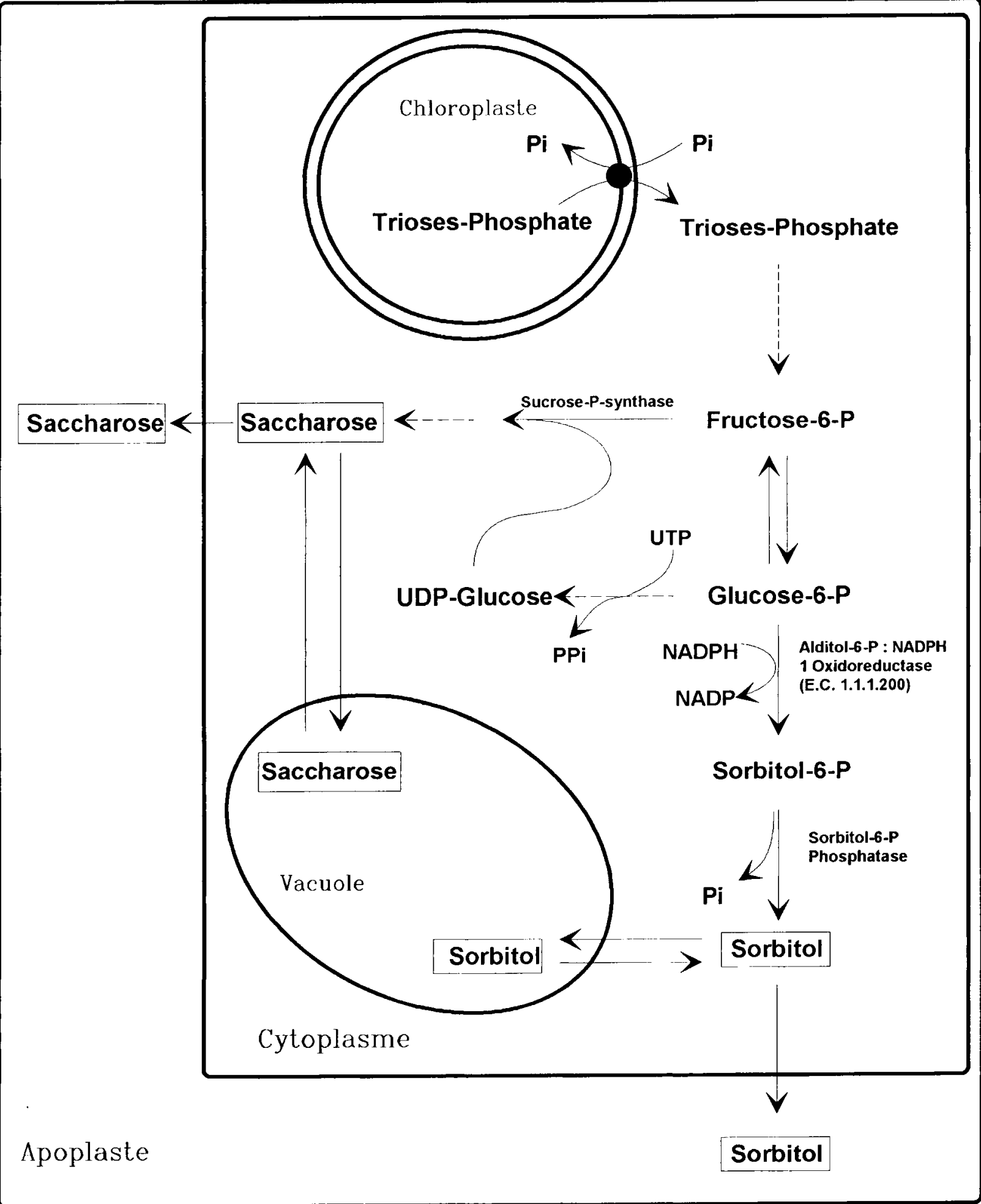

Fig 3. Voie de biosynthèse du sorbitol et du saccharose dans les cellules chlorophylliennes des feuilles adultes (d'après Bieleski et Redgwell, 1977; Redgwell et Bieleski, 1978; Grant et ap Rees, 1981; Loescher, 1987). 
Les alditols peuvent être formés soit par la réduction des hexoses phosphates (Bieleski et Redgwell, 1977 ; Redgwell et Bieleski, 1978), soit par réduction des hexoses (Bliss, 1972 ; Bieleski, 1982). Dans les plantes supérieures à alditols qui on été étudiées c'est la première possibilité qui a été mise en évidence. Redgwell et Bieleski (1978) ont montré que, chez les jeunes feuilles d'abricotier, le sorbitol-1-phosphate et le sorbitol6-phosphate sont rapidement synthétisés à partir des premiers produits de la photosynthèse. D'autre part, Loescher et al (1992) ont montré que, chez le céleri, le mannose-6-phosphate et le mannitol-1-phosphate sont parmi les premiers produits photosynthétiques marqués. Des résultats similaires ont été récemment obtenus par Simier et al (1994) chez l'hémiparasite de blé Thesium humile Vahl. Ils renforcent l'idée que les hexoses-phosphates constituent le point de départ pour la synthèse des alditols.

\section{Métabolisme du sorbitol et des sucres}

Les résultats obtenus avec ce type d'expériences dépendent des organes et des produits testés. Ainsi, lorsque du glucose, du fructose ou du saccharose sont fournis à des tissus qui contiennent des alditols, en particulier à des tissus foliaires, ces trois sucres peuvent être rapidement et largement transformés en polyol correspondant. Tel est le cas du mannitol chez les Oleaceae (Bieleski, 1982), et du sorbitol chez les Rosaceae (Bieleski, 1977). En effet, le sorbitol peut être synthétisé par les feuilles à partir d'hexoses exogènes, par exemple à partir du glucose chez le prunier (Anderson et al, 1962), le pommier (Hutchinson et al, 1959, cités par Whetter et Taper, 1963) et le poirier (Bieleski, 1977), à partir du fructose chez le pommier (Grant et ap Rees, 1981), et à partir du saccharose chez le pêcher (Escobar-Gutiérrez, 1995). La feuille est donc le principal organe de synthèse des alditols. Dans les plantules de pommier et de pêcher, elle constitue le seul tissu capable d'une conversion importante de fructose (Grant et ap Rees, 1981) et de saccharose (Escobar-Gutiérrez et al, 1994) exogènes en sorbitol. Cette conversion ne dépend pas de la lumière (Escobar-Gutiérrez et al, 1994). Grant et ap Rees (1981) ont montré qu'à la lumière $43 \%$ du fructose absorbé sont transformés en sorbitol et $11 \%$ en saccharose. À l'obscurité, $31 \%$ est transformé en sorbitol et $8 \%$ en saccharose. En revanche, dans l'écorce et les racines, seulement 1 à $2 \%$ du fructose est transformé en sorbitol. Chez certaines angiospermes parasites et hémisparasites non photo- synthétiques, les polyols peuvent être synthétisés à partir d'autres glucides (Lewis, 1984b). Toutefois, on ignore si la transformation s'effectue via les hexoses-phosphate ou directement par réduction des hexoses (Bieleski, 1982).

Les pointes de racine de pommier ne transforment pas le fructose en sorbitol (Grant et ap Rees, 1981). En revanche, elles sont capables de métaboliser le sorbitol et d'incorporer une partie de la radioactivité contenue dans celui-ci dans des composés insolubles. Par ailleurs, les nectaires floraux des rosacées ne sont pas capables de transformer le saccharose en sorbitol (Bieleski et Redgwell, 1980).

Les feuilles adultes sont capables de synthétiser rapidement du sorbitol à partir des produits de la photosynthèse (Moing et al, 1992 ; Escobar-Gutiérrez, 1995) ou par transformation de sucres exogènes mais ceci relativement très lentement (Escobar-Gutiérrez et al, 1994). Ainsi, quand un polyol est fourni à une feuille, il s'accumule. Cela suggère que la conversion du polyol en sucre ne s'effectue que très lentement. Par exemple, des lanières de feuilles de poirier accumulent du sorbitol lorsqu'on leur fournit soit du glucose soit du sorbitol (Bieleski, 1977). De la même façon, les feuilles adultes détachées de pêcher ne dégradent pas le sorbitol fourni par le flux transpiratoire (Escobar-Gutiérrez et al, 1994). En revanche, une importante transformation du sorbitol en d'autres sucres a lieu dans les fleurs et, au moins partiellement, dans leurs nectaires. La transformation du sorbitol pendant la sécrétion du nectar, aurait lieu au moment du déchargement du phloème (Bieleski et Redgwell, 1980).

Des recherches sur le métabolisme des sucres et du sorbitol en particulier, ont été menées chez la pomme par Hansen (1970), Berüter et Kalberer (1983), Priestley (1983) et Berüter (1985). On peut conclure que dans les fruits, le sorbitol est rapidement transformé en saccharose, fructose et glucose. Cependant, lorsque ces derniers sucres sont fournis au fruit, ils sont interconvertis entre eux, mais jamais transformés en sorbitol.

Toutes ces observations ont conduit à penser que les voies de synthèse et d'utilisation des alditols sont différentes et sont sous un contrôle indépendant (Bieleski, 1982).

\section{Les enzymes du métabolisme du sorbitol}

Entre la revue de Lewis et Smith (1967) et celles de Bieleski (1982) et Lewis (1984b), les connais- 
sances concernant le métabolisme des alditols avaient peu progressé. Depuis, des progrès considérables ont été réalisés dans le domaine de l'enzymologie du métabolisme du sorbitol et du mannitol en particulier. En effet, les travaux concernant la détection, l'isolement et la caractérisation des enzymes du métabolisme du sorbitol et du mannitol ont été nombreux pendant les années 1980 .

\section{Les enzymes de synthèse}

L'analyse enzymatique (Yamaki, 1980a ; Hirai, 1981 ; Negm et Loescher, 1981), les études sur les relations source-puits (Loescher et al, 1982 ; Merlo et Passera, 1991), ainsi que les études au moyen d'un marquage radioactif (Grant et ap Rees, 1981 ; Bieleski et Redgwell, 1985), ont établi que la synthèse du sorbitol est confinée principalement aux feuilles sources, alors que l'utilisation métabolique est limitée aux tissus puits.

Dans les feuilles adultes, la biosynthèse $\mathrm{du}$ sorbitol est réalisée par l'enzyme sorbitol-6-phosphate déshydrogénase (S-6-PDH), aussi nommée aldose-6-phosphate réductase NADPHdépendante (alditol-6-P:NADP 1 oxydoréductase, EC.1.1.1.200). Cette enzyme catalyse la conversion du glucose-6-phosphate en sorbitol-6-phosphate (Hirai, 1981). Le sorbitol-6-phosphate est à son tour converti en sorbitol par l'action d'une sorbitol-6-phosphate phosphatase spécifique (Grant et ap Rees, 1981) (fig 3).

Les études enzymatiques ont abouti à la purification de l'enzyme sorbitol-6-phosphate déshydrogénase du néflier du Japon par Hirai (1981) et à la production d'anticorps contre cette enzyme (Hirai, 1983). Très récemment, la S-6-PDH de plantules de pommier a été purifiée par Kanayama et Yamaki (1993). Le premier clonage d'un gène du métabolisme des alditols chez les végétaux a été réalisé par l'équipe japonaise du Dr Yamaki (Kanayama et al, 1992).
Dans les semences de maïs en germination, la synthèse du sorbitol utilise une autre voie. En effet, dans l'albumen la sorbitol est synthétisé à partir du fructose par l'enzyme cétose réductase $\mathrm{NADH}$-dépendante, nommée sorbitol déshydrogénase (SDH-NAD) (Doehlert, 1987 ; Doehlert et al, 1993). Dans les feuilles d'Evonymus spp, le galactitol est produit à partir du galactose sous l'action de l'enzyme galacticol : aldose réductase NADPH-dépendante (EC 1.1.1.21) (Negm, 1986).

\section{Les enzymes de dégradation}

À ce jour, trois enzymes de dégradation du sorbitol ont été mises en évidence chez les plantes supérieures (fig 4). La sorbitol déshydrogénase NAD-dépendante ou SDH-NAD (EC 1.1.1.14.) (Negm et Loescher, 1979 ; Yamaguchi et al, 1994) transforme le sorbitol en fructose. La deuxième enzyme de dégradation est la sorbitol oxydase NAD NADP-indépendante (SOX), qui transforme la sorbitol en glucose (Yamaki, 1980 b). La troisième enzyme est la sorbitol déshydrogénase NADP-dépendante ou SDHNADP (Yamaki et Ishikawa, 1986), qui transforme le sorbitol en glucose. Cette dernière semblerait avoir un rôle mineur dans le métabolisme du sorbitol (Yamaki et Ishikawa, 1986).

Les cellules hétérotrophes de cals de pommier et de poirier métabolisent le sorbitol grâce à la SDH-NAD. En fait, c'est dans ce matériel que la première enzyme du métabolisme du sorbitol chez les plantes supérieures a été mise en évidence (Negm et Loescher, 1979).

Dans les tissus de pommes (Yamaki et Ishikawa, 1986) et des poires japonaises (Yamaki et Moriguchi, 1989), l'activité de la SDH à NAD fluctue avec l'accumulation des glucides. Cependant, aucune corrélation n'a été trouvée entre l'activité SDH à NAD extractible et les taux de glucides solubles chez les pommes (Marlow et Loescher, 1985). Par ailleurs, les pêches présentent une forte activité de l'enzyme sorbitol
Fig 4. Voies métaboliques de dégradation du sorbitol chez les plantes supérieures. Les trois enzymes référées sont: $\mathrm{SDH}$ NAD, sorbitol déshydrogénase NADdépendante (EC 1.1.1.14); SOX, sorbitol oxydase NAD NADP-indépendante et SDH-NADP, sorbitol déshydrogénase NADP-dépendante (d'après Negm et Loescher, 1979; Yamaki, 1980b; Yamaki et Ishikawa, 1986 et Yamaguchi et al, 1994).

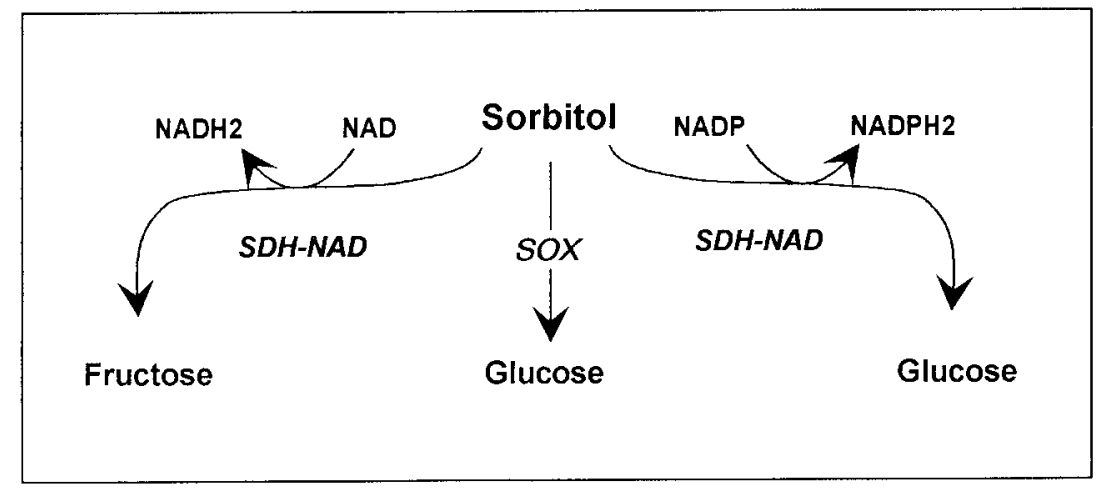


oxydase (SOX) et très peu d'activité pour les autres enzymes du métabolisme du sorbitol (Moriguchi et al, 1990).

Swedlund et Locy (1993) ont montré que l'apport de carbone sous forme de sorbitol dans le milieu de culture, favorise le développement de cals embryogènes (régénérables) de maïs. De plus, une activité SDH-NAD est présente dans ce type de cellules mais absente des cals nonembryogènes (non-régénérables). Par ailleurs, l'activité SDH-NAD a été détectée également dans l'albumen des grains de maïs accumulant du sorbitol (Doehlert, 1987 ; Doehlert et al, 1993). Cependant, il reste à savoir si dans les graines l'enzyme fonctionne dans le sens de la synthèse ou de la dégradation du sorbitol.

Enfin, Negm et Loescher (1981) ont rapporté des différences dans les activités enzymatiques S-6-PDH et SDH-NAD entre les feuilles jeunes et adultes. Lorsqu'une feuille se développe, elle passe d'un stade «puits» à un stade «source», et une forte diminution de l'activité SDH coïncide avec une augmentation de l'activité S-6-PDH (Loescher et al, 1982).

\section{Isoenzymes et induction enzymatique}

L'existence d'isoenzymes n'a pas été vraiment recherchée systématiquement. Cependant, le polymorphisme de 10 systèmes enzymatiques incluant la SDH ont été utilisé par Jarret et Litz (1986) pour différencier quatre clones de bananier (Cavendish Musa acuminata Colla). Les zymotypes de la SDH ont été révélés comme étant des triplets de bandes (trois formes de la même enzyme).

La possibilité que les sytèmes enzymatiques de synthèse ou de dégradation du sorbitol chez les plantes soient inductibles a été étudiée uniquement pour la sorbitol-6-phosphate déshydrogénase qui augmente en quantité et en activité dans les feuilles de néflier du Japon soumis à de basses températures (Hirai, 1983).

\section{Cytolocalisation des voies de synthèse du sorbitol}

Les premières évidences suggéraient que la synthèse du sorbitol avait lieu dans les chloroplastes (De Villier, 1978) ou dans les chloroplastes et le cytosol (Yamaki, 1981). La localisation chloroplastique de la synthèse du sorbitol a été remise en question par Lewis (1984b) et Rumpho et al (1983). Les résultats de Lewis (1984b), obtenus avec des disques de feuilles de pommier, de prunier et de Plantago, soumises in vitro à un appauvrissement en $\mathrm{Pi}$, sont en faveur d'une synthèse cytoplasmique du sorbitol. Cette synthèse cytoplasmique des polyols a été confirmée chez le céleri par fractionnement cellulaire (Rumpho et al, 1983) et par immunocytolocalisation (Everard et al, 1993).

\section{REMERCIEMENTS}

Les auteurs tiennent à remercier A Moing pour ses critiques et suggestions.

\section{RÉFÉRENCES}

Ahmad T, Larher F, Stewart GR (1979) Sorbitol, a compatible osmotic solute in Plantago maritima. New Phytol 82, 671-678

Anderson JD, Andrews P, Hough L (1961) The biosynthesis and metabolism of polyols. Sorbitol (D-glucitol) of plum leaves. Biochem J 81, 149-154

Anderson JD, Andrews P, Hough L (1962) The biosynthesis and metabolism of polyols. II. The metabolism of ${ }^{14} \mathrm{C}$-labelled glucose, D-glucuronic acid and D-glucitol (sorbitol) by plum leaves. Biochem $J 84$, 140-146

Berüter J (1985) Carbohydrate partitioning and changes in water relations of growing apple fruit. J Plant Physiol 121, 311-341

Berüter $J$ (1989) Sugar accumulation and changes in activities of related enzymes during development of the apple fruit. J Plant Physiol 135, 583-587

Berüter J, Kalberer PP (1983) The uptake of sorbitol by apple fruit tissue. $Z$ Pflanzenphysiol 110, 113125

Bieleski RL (1969) Accumulation and translocation of sorbitol in apple phloem. Aust J Biol Sci 22, 611 620

Bieleski RL (1977) Accumulation of sorbitol and glucose by leaf slices of Rosaceae. Aust J Plant Physiol $4,11-24$

Bieleski RL (1982) Sugar alcohols. In: Plant Carbohydrates. I. Intracellular carbohydrates (FA Loewus, W Tanner, eds) Encyclopedia of Plant Physiol, New series 13A, Springer-Verlag, Berlin, 158-192

Bieleski RL, Redgwell RJ (1977) Synthesis of sorbitol in apricot leaves. Aust J Plant Physio/ 4, 1-10

Bieleski RL, Redgwell RJ (1980) Sorbitol metabolism in nectaries from flowers of Rosaceae. Aust J Plant Physiol 7, 15-25

Bieleski RL, Redgwell RJ (1985) Sorbitol versus sucrose as photosynthesis and translocation products in developing apricot leaves. Aust J Plant Physiol 12, 657-668 
Bliss CA, Hamon NW, Lukaszewski TP (1972) Biosynthesis of dulcitol in Euonymus japonica. Phytochemistry 11, 1705-1711

Boussingault $J$ (1872) Sur la sorbite, matière sucrée analogue à la mannite, trouvée dans le jus des baies du sorbier des oiseleurs. C R Acad Sci Paris 74, 939-942

Briens M, Larher F (1983) Sorbitol accumulation in Plantaginaceae; further evidence for a function in stress tolerance. Z Pflanzenphysiol 110, 447-458

Brooks SJ, Moore JN, Murphy JB (1993) Quantitive and qualitative changes in sugar content of peach genotypes (Prunus persica (L) Batsch). J Amer Soc Hort Sci 118, 97-100

Chan WW, Chong C, Taper CD (1972) Sorbitol and other carbohydrate variation during growth and cold storage of Mclntosh apple fruits. Can J Plant Sci 52, 743-750

Chong $C$ (171) Study of seasonal and daily distribution of sorbitol and related carbohydrates within apple seedlings by analysis of selected tissues and organs. Can J Plant Sci 51, 519-525

Chong C, Taper CD (1971a) Daily variation of sorbitol and related carbohydrates in Malus leaves. Can $J$ Bot 49, 173-177

Chong C, Taper CD (1971b) Effect of solar radiation on seasonal concentration of sorbitol and related carbohydrates in apple leaves. Can J Plant Sci 51, 551-553

Daie J (1987) Sucrose uptake in isolated phloem of celery in a single saturable transport system. Planta $171,474-482$

Davis JM, Loescher WH (1990) $\left[{ }^{14} \mathrm{C}\right]$-Assimilate translocation in the light and dark in celery (Apium graveolens) leaves of different ages. Physiol Plant 79 , 656-662

Davis JM, Loescher WH (1991) Diurnal pattern of carbohydrates in celery leaves of various ages. Hortscience 26, 1404-1406

Davis JM, Fellman JK, Loescher WH (1988) Biosynthesis of sucrose and mannitol as a function of leaf age in celery (Apium graveolens). Plant Physiol 86, 129-133

De Villiers OT (1978) Incorporation of ${ }^{14} \mathrm{CO}_{2}$ into sorbitol and other metabolites in chloroplasts of Prunus salicina, Lindl leaves. South African J Sci 74, 342343

Doehlert DC (1987) Ketose reductase activity in developing maize endosperm. Plant Physiol 84, 830-834

Doehlert DC, Kuo TM, Juvik JA, Beers EP, Duke SH (1993) Characteristics of carbohydrate metabolism in sweet corn (sugary-1) endosperms. J Am Soc Hortic Sci 118, 661-666

Drew EA (1984) Physiology and metabolism of cyclitols. In: Storage Carbohydrates in Vascular Plants (DH Lewis, ed), Cambridge University Press, Cambridge, 134-155

Escobar-Gutiérrez AJ (1995) Photosynthèse, partition du carbone et métabolisme du sorbitol dans les feuilles adultes de pêcher (Prunus persica (L) Batsch). Thèse de docteur de l'université de Poitiers, France

Escobar-Gutiérrez AJ, Gaudillère JP (1994) Variabilité in sorbitol:sucrose ratios in mature leaves of different peach cultivars. J Am Soc Hortic Sci 119, 321 . 324

Escobar-Gutiérrez AJ, Carbone F, Gaudillère JP (1994) Apoplastic sucrose and sorbitol metabolism in peach leaves. In: Plant Sciences 1994 (Y de Kouchkovsky, F Larher, eds), Société Française de Physiologie Végétale, Paris, 128

Everard JD, Franceschi VR, Loescher WH (1993) Mannose-6-phosphate reductase, a key enzyme in photoassimilate partitioning in abundant and located in the cytosol of photosynthetically active cells of celery (Apium graveolens L) source leaves. Plant Physiol 102, 345-356

Everard JD, Gucci R, Kann SC, Flore JA, Loescher WH (1994) Gas exchange and carbon partitioning in leaves of celery (Apium graveolens $L$ ) at various levels of root salinity. Plant Physiol 106, 281-292

Fellman JK, Loescher W (1987) Comparative studies on sucrose and mannitol utilization in celery (Apium graveolens L). Physiol Plant 69, 337-341

Fox TC, Kennedy RA, Loescher WH (1986) Developmental changes in photosynthetic gas exchange in the polyol-synthetizing species, Apis graveolens L (celery). Plant Physiol 82, 307-311

Fromard L (1990) Étude du transport des glucides entre les cellules associées aux vaisseaux (cav) et les vaisseaux chez Acer platanoides et Robinia pseudoacacia. Incidence des facteurs saisonniers et climatiques. Thèse de docteur de l'université de Poitiers, France

Gaudillère JP, Moing A (1992) Photosynthesis of peach leaves: light adaptation, limitting factors and sugar content. Acta Hortic 315, 103-109

Gaudillère JP, Moing A, Escobar AJ (1991) Sorbitol metabolism in Prunus persica. In: Plant Science Today (Y de Kouchkovsky, ed) Inra Éditions, Paris, 142

Gaudillère JP, Moing A, Carbonne F (1992) Vigour and non-structural carbohydrates in young prune trees. Scientia Hortic 51, 197-211

Generozova IP, Andreev VY, Vartapetian VV, Vartapetian BB (1990) Mitochondrial ultrastructure and carbohydrate dynamics in apple-tree fruits under conditions of strong anoxia. Fiziologia Rastenii 37, 271-280

Grant CR, ap Rees T (1981) Sorbitol metabolism by apple seedlings. Phytochemistry 20, 1505-1511

Hansen P (1970) ${ }^{14} \mathrm{C}$-studies on apple trees. V. Translocation of labelled compounds from leaves to fruit and their conversion within the fruit. Physiol Plant 23, 564-573

Hansen P, Grausland J (1973) ${ }^{14} \mathrm{C}$-studies on apple trees. VIII. The seasonal variation and nature of reserves. Physiol Plant 28, 24-32 
Hansen P, Grausland J (1978) Levels of sorbitol in bleeding sap and in xylem sap in relation to leaf mass and assimilate demand in apple trees. Physiol Plant 42, 129-133

Hirai M (1981) Purification and characteristics of sorbitol-6-phosphate dehydrogenase from loquat leaves. Plant Physiol 67, 221-224

Hirai M (1983) Seasonal changes in sorbitol-6-phosphate dehydrogenase in loquat leaf. Plant Cell Physiol 24, 925-931

Jarret RL, Litz RE (1986) Isozymes as genetic markers in bananas and plantains. Euphytica 35, 539-549

Jefferies RL, Rudmik T, Dillon EM (1979) Responses of halophytes to high salinities and low water potentials. Plant Physiol 64, 989-994

Jones HG, Lakso A, Syvertsen JP (1985) Physiological control of water status in temperate and subtropical fruits trees. Hortic Rev 7, 301-344

Kanayama Y, Mori H, Imaseki G, Yamaki S (1992) Nucleotide sequence of a CDNA encoding NADPsorbitol-6-phosphate dehydrogenase from apple. Plant Physiol 100, 1607-16078

Kanayama Y, Yamaki S (1993) Purification and properties of NADP dependent sorbitol-6-phosphate dehydrogenase from apple seedlings. Plant Cell Physiol 34, 819-823

Keller F (1989) Biochemistry and physiology of nonfructan sucrosyl-oligosaccharides and sugar alcohols in higher plants. J Plant Physiol 134, 141-147

Keller F, Matile P (1989) Storage of sugars and mannitol in petioles of celery leaves. New Phytol 113, 291-299

Lambers H, Blacquière T, Stuvier B (CEE) (1981) Interaction between osmoregulation and the alternative respiratory pathway in Plantago coronopus as affected by salinity. Physiol Plant 51, 63-68

Lewis $\mathrm{DH}$ (1984a) Occurence and distribution of storage carbohydrates in vascular plants. In: Storage Carbohydrates in Vascular Plants (DH Lewis, ed), Cambridge University Press, Cambridge, 1-52

Lewis DH (1984b) Physiology and metabolism of alditols. In: Storage Carbohydrates in Vascular Plants (DH Lewis, ed), Cambridge University Press, Cambridge, 157-179

Lewis DH, Smith DC (1967) Sugar alcohols (polyols) in fungi and green plants. I. Distribution, physiology, and metabolism. New Phytol 66, 143-184

Loescher WH (1987) Physiology and metabolism of sugar alcohols in higher plants. Physiol Plant 70, 553-557

Loescher WH, Marlow GC, Kennedy RA (1982) Sorbitol metabolism and sink-source interconversion in developing apple leaves. Plant Physiol 70, 335-339

Loescher WH, Fellman JK, Fox TC, Davis JM, Redgwell RJ, Kennedy RA (1985) Other carbohydrates as translocated carbon sources: acyclic polyols and photosynthetic carbon metabolism. In: Regulation of Carbon Partitioning in Photosynthetic
Tissue (RL Heath, J Preiss, eds), Rockwille, MD, 309-332

Loescher WH, Tyson RH, Everard JD, Redgwell RJ, Bieleski RL (1992) Mannitol synthesis in higher plants. Plant Physiol 98, 1396-1402

Marlow GC, Loescher WH (1985) Sorbitol metabolism, the climacteric, and watercore in apples. J Am Soc Hortic Sci 110, 676-680

Merlo L, Passera C (1991) Changes in carbohydrate and enzyme levels during development of leaves of Prunus persica, a sorbitol synthesizing species. Physiol Plant 83, 621-626

Moing A, Carbonne F, Rashad MH, Gaudillère JP (1992) Carbon fluxes in mature peach leaves. Plant Physiol 100, 1878-1884

Moing A, Escobar-Gutiérrez AJ, Gaudillère JP (1994) Modeling carbon export out of mature peach leaves. Plant Physiol 106, 591-600

Moore DM (1985) Plantaginales. In: Flowering Plants of the World (VH Heywood, ed), Croom Helm Publ, Londres, 241

Moriguchi T, Sanada T, Yamaki S (1990) Seasonal fluctuation of some enzymes relating to sucrose and sorbitol metabolism in peach fruit. $J$ Am Soc Hortic Sci 115, 278-281

Negm FB (1986) Purification and properties of an NADPH-aldose reductase (aldehyde reductase) from Euonymus japonica leaves. Plant Physiol 80, 972-977

Negm FB, Loescher WH (1979) Detection and characterization of sorbitol dehydrogenase from apple callus tissue. Plant Physiol 64, 69-73

Negm FB, Loescher WH (1981) Characterization and partial purification of aldose-6-phosphate reductase (alditol-6-phosphate:NADP 1-oxidoreductase) from apple leaves. Plant Physiol 67, 139-142

Nii N (1993) Anatomical features of the sieve elements in the vascular bundles of Rosaceae fruit trees. $J$ Jpn Soc Hortic Sci 62, 55-61

Nii N, Katsunori H, Uchida H (1994) Anatomical features of the sieve elements and sorbitol content in various organs of Rosaceae fruit trees. J Jpn Soc Hortic Sci 62, 739-747

Pavel EW, DeJong TM (1993) Relative growth rate and its relationship to compositional changes of nonstructural carbohydrates in the mesocarp of developing peach fruits. J Am Soc Hortic Sci 118, 503-508

Plouvier V (1963) Distribution of aliphatic polyols and cyclitols. In: Chemical Plant Taxonomy (T Swain, ed), Academic Press, London, 313-336

Plouvier V (1971) Sur la recherche du scyllitol, du myo-inositol et du dulcitol dans quelques groupes botaniques. CR Acad Sci Paris, série D 242, 141 144

Priestley CA (1983) Interconversions of ${ }^{14} \mathrm{C}$-labelled sugars in apple tree tissues. $J$ Exp Bot 34, 17401747 
Raese JT, Williams MW, Billingsley HD (1978) Cold Hardiness, sorbitol, and sugar levels of apple shoots as influenced by controlled temperature and season. J Am Soc Hortic Sci 103, 796-801

Ranney TG, Bassuk NL, Whitlow TH (1991) Osmotic adjustment and solute constituents in leaves and roots of water-stress cherry (Prunus) trees. J Am Soc Hortic Sci 116, 684-688

Raynal-Roques A (1994) La botanique redécouverte. Belin-Inra Éditions, Paris

Redgwell RJ, Bieleski RL (1978) Sorbitol-1-phosphate and sorbitol-6-phosphate in apricot leaves. Phytochemistry 17, 407-409

Rohrbach KG, Luespschen NS (1968) Seasonal changes in sugar alcohols and sugars in peach bark: a possible relationship to cytospora canker susceptibility. Proc Am Soc Hortic Sci 93, 135-140

Rowley GD (1985) Rosaceae. The rose family. In: Flowering Plants of the World (VH Heywood, ed), Croom Helm Publ, Londres

Rumpho ME, Edwards GE, Loescher WH (1983) A pathway for photosynthetic carbon flow to mannitol in celery leaves. Plant Physiol 73, 869-873

Sakai A (1961) Effect of polyhydric alcohols to frost hardiness in plants. Nature 189, 416-417

Sakai A (1966) Seasonal variations in the amounts of polyhydric alcohol and sugar in fruit trees. $J$ Hortic Sci $41,207-213$

Shaw JR, Dickinson DB (1984) Studies of sugar and sorbitol in developing corn kernels. Plant Physiol 75, 207-211

Simier P, Fer A, Renaudin S (1993) Identification of the main osmotically active solutes in the unstressed and water-stressed root-hemiparasitic angiosperm Thesium humile and its host Triticum vulgare. Aust J Plant Physiol 20, 223-230

Simier P, Renaudin S, Fer A (1994) Characteristics of the mannitol pathway in a root hemiparasitic specie, Thesium humile Vahl (Santalaceae). J Plant Physiol $1143,33-38$

Suleman P, Steiner W (1994) Relationship between sorbitol and solute potential in apple shoots relative to fire blight symtom development after infection by Erwinia amylovora. Phytopathology 84, 1244-1250

Swedlund B, Locy RD (1993) Sorbitol as the primary carbon source for the growth of embryogenic callus of maize. Plant Physiol 103, 1339-1346

Tao R, Uratsu SL, Dandekar AM (1995) Sorbitol synthesis in transgenic tobacco with apple cDNA encoding NADP-dependent sorbitol-6-phosphate dehydrogenase. Plant Cell Physiol 36, 525-535

Taper CD, Liu PS (1969) Sorbitol occurrence in Malus leaves and fruits. Can J Plant Sci 49, 97-98

Tarczynski MC, Jensen RG, Bohnert HJ (1992) Expression of a bacterial $m t / D$ gene in transgenic tobacco leads to production and accumulation of mannitol. Proc Natl Acad Sci USA 89, 2600-2604
Tarczynski MC, Jensen RG, Bohnert HJ (1993) Stress protection of transgenic tobacco by production of the osmolyte mannitol. Science 259, 508-510

Thomas JC, Sepahi M, Arendall B, Bohnert HJ (1995) Enhancement of seed germination in seed germination in high salinity by engineering mannitol expression in Arabidopsis thaliana. Plant Cell Environ 18, 801-806

Wallaart RAM (1980) Distribution of sorbitol in Rosaceae. Phytochemistry 19, 2603-2610

Wallaart RAM (1981) Acyclic polyols as taxonomic characters. II. Sorbitol in Plantaginaceae and joint occurrence of sorbitol and mannitol in some Plantago species. Proc Koninklijke Nederlandse Akademie von Wetenschappen, series C, 84, 77-82

Wang Z, Stutte GW (1992) The role of carbohydrates in active osmotic adjustement in apple under water stress. J Am Soc Hortic Sci 117, 816-823

Webb KL, Burley JWA (1962) Sorbitol translocation in apple. Science 137, 766

Whetter JM, Taper CD (1963) Note on seasonal occurrence of sorbitol (D-glucitol) in buds and leaves of Malus. Can J Bot 41, 175-177

Whetter JM, Taper CD (1966) Occurrence of sorbitol (D-glucitol) and certain related sugars in germinating seeds and developing seedlings of Malus. Can $J$ Bot 44, 51-55

Williams MW, Billingsley HD (1973) Watercore development in apple fruits as related to sorbitol levels in the tree sap and to minimum temperatures. J Am Soc Hortic Sci 98 , 205-207

Williams MW, Raese JP (1974) Sorbitol in tracheal sap of apple as related to temperature. Physiol Plant 30, 49-52

Yamaguchi H, Kanayama Y, Yamaki S (1994) Purification and properties of NAD dependent sorbitol dehydrogenase from apple fruit. Plant Cell Physiol 35, 887-892

Yamaki S (1980a) Properties and functions of sorbitol6-phosphate dehydrogenase, sorbitol dehydrogenase and sorbitol oxidase in fruit and cotyledon of apple (Malus pumilla Mill var domestica Schneid). $J$ Jpn Soc Hortic Sci 49, 429-434

Yamaki S (1980b) A sorbitol oxidase that converts sorbitol to glucose in apple leaf. Plant Cell Physiol 21, 591-599

Yamaki S (1981) Subcellular localization of sorbitol-6phosphate dehydrogenase in protoplast from apple cotyledons. Plant Cell Physiol 22, 359-367

Yamaki S (1982) Distribution of sorbitol, neutral sugars, free amino acids, malic acid and some hydrolytic enzymes in vacuoles of apple cotyledons. Plant Cell Physiol 23, 881-889

Yamaki S (1984) Isolation of vacuoles from immature apple fruit flesh and compartmentation of sugars, organic acids, phenolic compounds and amino acids. Plant Cell Physiol 25, 881-889

Yamaki S, Ishikawa K (1986) Roles of four sorbitol related enzymes and invertase in the seasonal alte- 
ration of sugar metabolism in apple tissue. $J \mathrm{Am}$ Soc Hortic Sci 111, 134-137

Yamaki S, Moriguchi T (1989) Seasonal fluctuation of sorbitol related enzymes and invertase activities accompanying maturation of Japanese pear (Pyrus serotina Rehder var culta Rehder) fruit. J Jpn Soc Hortic Sci 57, 602-607

Ziegler H (1975) Nature of transported substances. In: Encyclopedia of Plant Physiology (MH Zimmermann, JA Milburn, eds) New series, Vol 1. Springer-Verlag, Berlin, 59-136
Zimmermann MH, Ziegler H (1975) List of sugar alcohols in sieve tube exudates. In: Encyclopedia of Plant Physiology (MH Zimmermann, JA Milburn, eds) New series, Vol 1, Springer-Verlag, Berlin, 480-503

Zipperlin B (1993) Étude de la variation des acides aminés et des sucres solubles en conditions de stress hydrique et de stress de blessure chez le pêcher (Prunus persica L Batsch). Étude particulier du gaba. Mémoire de DEA, Université de Poitiers, France 